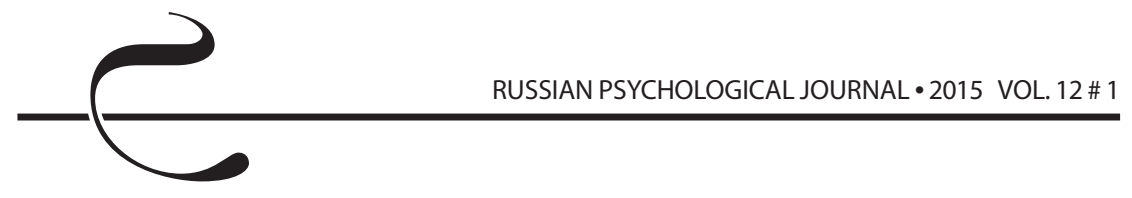

СОЦИАЛЬНАЯ ПСИХОЛОГИЯ

УДК 159.9.072.43

\title{
ОСОБЕННОСТИ САМООТНОШЕНИЯ И САМОЭФФЕКТИВНОСТИ ЛИЧНОСТИ КАК ПРЕДИКТОРЫ ЕЕ ОБРАЗОВ ВРАГА
}

\section{Альперович Валерия Дмитриевна}

Исследование выполнено при финансовой поддержке ЮФу

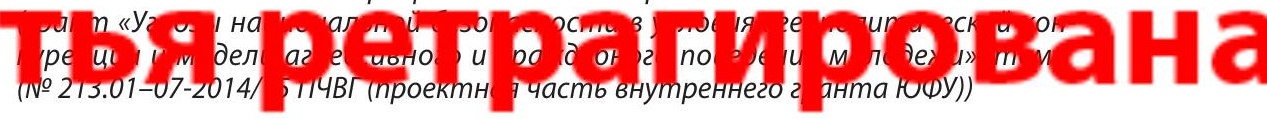

В статье затронута проблема влияния самоотношения личности на ее представления о Другом человеке. Проблемой нашего исследования стало влияние самоотношения и самоэффективности на особенности представлений личности о Враге. Цель данного исследования заключалась в выявлении

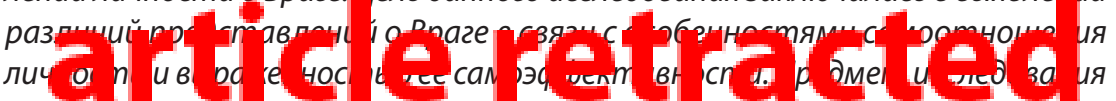
составили социально-психологические характеристики представлений личности о Враге, особенности ее самоотношения, уровень выраженности ее самоэффективности. Применены качественные и количественные методы (тестирование, субъективное шкалирование, категориальный, частотный, кластерный анализ). Показано, что респонденты, воспринимающие Врага в качестве агрессора, манипулятора, носителя отричательных качеств,

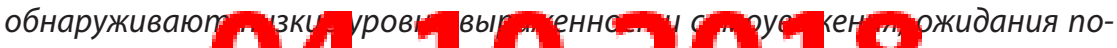

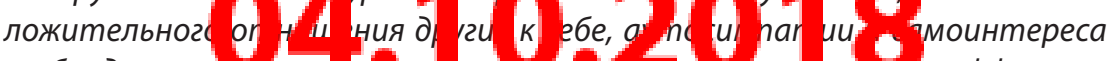
и обладают, в чсновно, низиим уровнел оорапеннсти самоэффективности; респонденты, воспринимающие Врага в качестве когнитивно и ценностно чуждого им субъекта, недоброжелательно относящегося к ним, обнаруживают высокие уровни выраженности самоуважения, ожидания положительного отношения других к себе, аутосимпатии и самоинтереса и обладают, в основном, высоким уровнем выраженности самоэффективности. Данные свидетельствуют в пользу гипотезы о том, что социальнопсихологические характеристики представлений личности о Враге могут различаться в зависимости от особенностей ее самоотношения и уровня выраженности ее самоэффективности. Выводы по результатам исследования могут быть использованы в социально-психологическом 
консультировании, при разработке программ тренингов толерантности в антитеррористической деятельности, решения конфликтов в разных сферах взаимодействия.

Ключевые слова: представления, Враг, самоотношение, самоуважение, аутосимпатия, отношение других, самоинтерес, самоэффективность.

Актуальность изучс:'"n феноменов «Враг» и "Друг» в течение многих десятилетий обусловлена макроэкономическими трансформациями в разных странах, в т. ч. в современной России, усилением социальной нестабильности, обострением межэтнических и межкультурных конфликтов, подчас связанными с военными столкновениями, появлением беженцев,

в России, периодами экономических кризисов, сопровождаемыми сменой места работы, уменьшением материального благосостояния. В последние десятилетия данные процессы в разных странах предопределили постановку в гуманитарных науках, в т. ч. психологических, проблемы взаимодетерминации особенностей обыденного познания Другого в различных ипостасях: Друга/Врага, «своего»/«чужого», - конструирования его об-

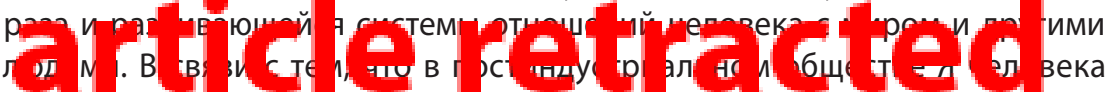
становится «протеевским» (Р. Дж. Лифтон) (текучим, неопределенным), увеличивается количество исследований, посвященных созданию и динамике образов Я, самоотношению. Самоотношение выступает необходимым звеном в саморегуляции личности, самоконтроле ее поведения, приобретающих особую значимость для нее в стрессогенных условиях социальной нестабильности. Самоотношение, по мнению ученых (Р. Бернс, И. С. Кон,

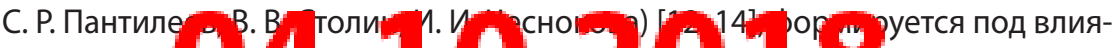

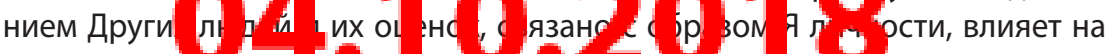
такие социально-психологические хараитеристики ияенилены, как копингстратегии, социально-психологический статус, мотивация достижения успеха. Конструирование образов Другого человека опосредствовано системой социальных категорий разной степени обобщенности («добро/зло», «Мы/ Они», «успех/неуспех» и пр.), необходимых для процессов самоопределения личности. Последнее неотделимо от формирования и динамики самоотношения личности и, в свою очередь, в частности в контексте выбора профессионального пути и регуляции социальной жизнедеятельности в целом, от такого феномена, как «самоэффективность личности».

Социальными психологами отмечено, что в качестве субъекта межличностных отношений (Л. Гудков, Г. И. Козырев, В. Н. Мясищев) [4, 7] и субъек- 


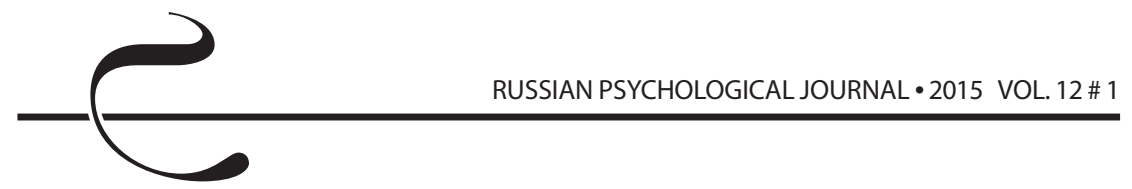

тов представлений (В. В. Знаков, Н. В. Чудова) $[6,16]$ Враг выступает членом иной группы с чуждыми убеждениями, отрицательными нравственными качествами, агрессивным, завистливым соперником, способным обмануть, предать, с непредсказуемым поведением. Враждебное отношение актуализируется во взаимодействии с другим человеком, воспринимаемым в качестве «чужого» (Ю. Э. Ширков, Т. А. Шкурко) [17, 18], «террориста» (Е. Д. Бреус, В. В. Знаков) $[1,6]$. Авторган зыявлены макрофакторы (общественная идеология, социально-экономическая ситуация в стране, влияние СМИ) (Т. П. Емельянова, W. Doise, J.-M. Seca) [5, 19, 20] и микрофакторы: система социальных идентичностей личности, социальная ситуация развития, референтные группы, отношения личности на определенном этапе жизненного

о Враге, так или иначевыраженные посредством системы отношений личности к себе и с другими людьми, воплощенные в ней. Изучаются взаимосвязи отношения к противнику (Врагу) и самооценки (В. М. Голянич, С. С. Грачев). Выявлено содержание феномена «самоотношение» как одномерного образования: суммы частных самооценок или интегральной самооценки (Р. Бернс, У. Джеймс, Ч. Кули), «чувства» (симпатии к себе, самоуверенности,

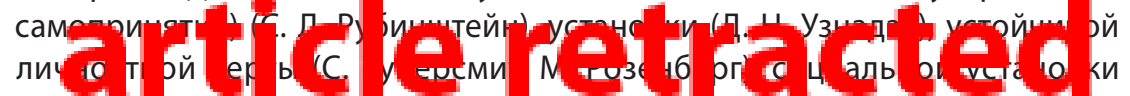
(И. С. Кон, Н. И. Сарджвеладзе), - и сложноструктурированного психического образования (С. Р. Пантилеев, В. В. Столин), в целом позитивного, негативного или конфликтного. Проанализирована структура самоотношения: выделен когнитивный, эмоциональный и конативный компоненты (Н. И. Сарджвеладзе), исследуется самоуважение, аутосимпатия, самоинтерес (близость к самому себе), ожидаемое отношение других, внутренние действия в адрес самого себя

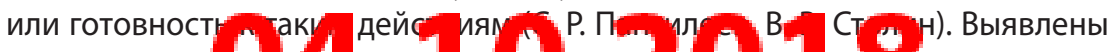
функции само тH ц ция сигнализации о сіиысе \& (В. Б. Столип), функции сохрапения внутренней стабильности, саморегуляции (А. М. Колышко, Н. И. Сарджвеладзе) [8]. Исследованы взаимосвязи самоотношения с другими личностными феноменами, прежде всего с образом Я (И. С. Кон, С. Р. Пантилеев, В. В. Столин, И. И. Чеснокова), в т. ч. в ситуациях успешности/неуспешности. Выявлено содержание феномена «самоэффективность» как представление человека о собственной возможности быть продуктивным, уверенность в успешной самореализации (А. Бандура, Р. Л. Кричевский, Дж. Маддукс, М. Шеер) [9], виды самоэффективности: в деятельности и общении (А. Бандура), деятельностный, коммуникативный и личностный (М. И. Гайдар) [2]. Изучаются взаимосвязи самоэффективности с другими личностными феноменами, социально- 
психологическими свойствами (карьерными ориентациями, самооценкой профессиональной деятельности, выбором копинг-стратегий поведения в межличностном конфликте, эмпатичностью, интернальностью, самопринятием, организаторскими способностями, коммуникативными свойствами, толерантностью), с самоотношением (М. И. Гайдар, Т. О. Гордеева, Е. А. Митицына, А. А. Погорелов) [3, 11, 13], образом Я (Р. Л. Кричевский). Изучается роль самоэффективности в рсг:ции социальной жизнедеятельности субъекта (М. И. Гайдар, С. Н. Гончар, Е. А. Митицына, А. Ю. Патрикеева). Несмотря на то, что социальными психологами показано влияние системы отношений личности на ее образы Других людей разных категорий (Друг/Враг, «свой»/«чужой» и т. п.), самооценки на отношение к противнику (Врагу), представлений личности о Враге,ее самоотношения исамоэффективности на эмпирическом уровне являются недостаточно изученными.

Исходя из затронутых работ и многих других, мы рассматриваем представления о Враге как динамичные когнитивно-эмоциональные образования, социально-психологические характеристики которых - личностные свойства, функции в общении, характеристики отношений, интерпретации поступков,

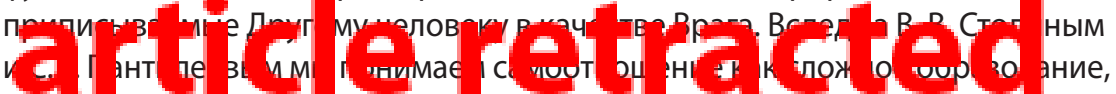
включающее психологические феномены разного уровня - общее, глобальное чувство «за» или «против» самого себя и более специфические параметры: самоуважение, аутосимпатию, самоинтерес (близость к самому себе), ожидаемое положительное отношение других и внутренние действия в адрес самого себя (или готовность к таким действиям). Вслед за Т. О. Гордеевой и Р. Л. Кричевским мы понимаем самоэффективность как комплекс личностных

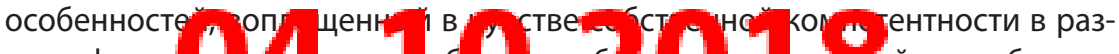

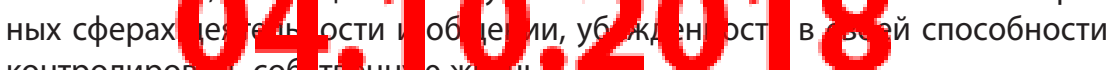
контролировань собетвенную жизнь.

В этой связи проблемой нашего исследования стало влияние самоотношения и самоэффективности на особенности представлений личности о Враге. Цель исследования заключалась в выявлении различий представлений о Враге в связи с самоотношением личности и выраженностью самоэффективности. Предмет исследования составили социально-психологические характеристики представлений личности о Враге, особенности ее самоотношения, уровень выраженности ее самоэффективности. Сформулированы следующие гипотезы исследования: 1. Особенности самоотношения личности и уровень выраженности ее самоэффективности могут быть взаимосвязаны. 2. Социально-психологические 


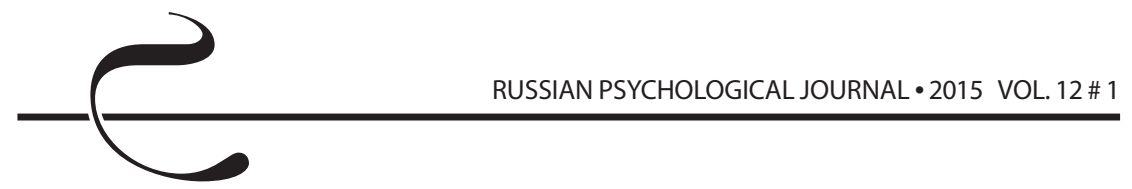

характеристики представлений личности о Враге могут различаться в зависимости от особенностей ее самоотношения и уровня выраженности ее самоэффективности. Нами применены следующие методы исследования: тестирование, субъективное шкалирование, частотный анализ, кластерный анализ, категориальный анализ. В данном исследовании нами использованы: 1) Модифицированная методика «Социально-психологические характеристики представлений о Друге и Врлгм. (В. Д. Альперович, 2010); 2) Тест-опросник самоотношения В. В. Столина, С. Р. Пантилеева; 3) Шкала общей самоэффективности Р. Шварцера, М. Ерусалема.

Методика «Социально-психологические характеристики представлений о Друге и Враге» (В. Д. Альперович, 2010), разработанная на основе метода

Данная методика включает незаконченные предложения, направленные на выявление социально-психологических характеристик, включенных респондентами в представления о Враге в настоящий период жизни и в прошлый период жизни. Методика позволяет выявить элементы в структуре представлений о Враге (например, «агрессивный», «обманывает»), называемые респондентами, объединяемые исследователем в группы,

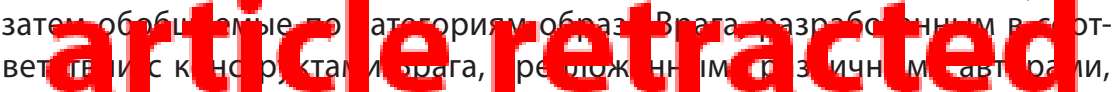
в т. ч. Д. Н. Тулиновой [15]. В качестве эмпирического объекта исследования выступили 50 человек: 5 юношей, 45 девушек в возрасте 21-23 лет (студенты 4 курса факультета психологии Южного федерального университета г. Ростова-на-Дону). В сборе и обработке данных эмпирического исследования участвовала студентка Ю. Н. Гринькова, под руководством В. Д. Альперович. Выбор эмпирического объекта обусловлен целью и предметом исследования,

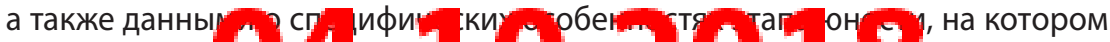
происходит р зв т А ефлен ии ф омул ј построение системы ценпостй, наиболес бобобщенных, нйотенциально реализуемых жизненных планов.

На первом этапе исследования выявлены социально-психологические характеристики представлений респондентов о Враге. На втором этапе исследования определен уровень выраженности самоэффективности участников исследования с различными социально-психологическими характеристиками представлений о Враге. На третьем этапе исследования установлены особенности самоотношения участников исследования с разными социально-психологическими характеристиками представлений о Враге. Структурный анализ представлений респондентов о Враге был выполнен посредством частотного анализа групп элементов представлений, 
позволяющего определить «ядерные» и «периферические» группы элементов представлений о Враге.

У 36 \% респондентов наиболее насыщенной является группа элементов «Вредность, насильственность, агрессивность действий» (52-75 \% ответов каждого респондента), которая входит в категорию «Активный участник конфликтной интеракции». Эта группа респондентов воспринимает Врага главным образом как агргглnа. Среди данных респондентов 77,8 \% обладают низким уровнем самоэффективности, 11,1\% респондентов - высоким уровнем самоэффективности, 11,1 \% респондентов - средним уровнем самоэффективности. У 50 \% респондентов данной группы не выражено самоуважение, у $27,8 \%$ респондентов оно выражено; у 22,2 \% респондентов ярко выражено

имеют ярко выраженную аутосимпатию. У 72,2 \% респондентов не выражено ожидание положительного отношения других к себе, у 27,8 \% респондентов ожидание положительного отношения других к себе выражено. У 72,2 \% респондентов не выражен самоинтерес. У 16,7 \% участников исследования он ярко выражен. У 11,1 \% респондентов выражен самоинтерес.

У 26 \% респондентов наиболее насыщенной является группа элементов

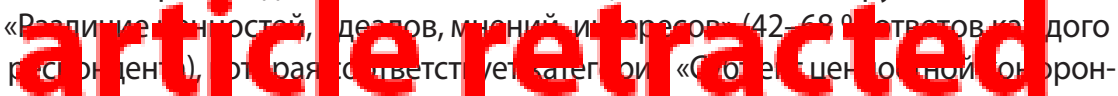
тации». Эта группа респондентов воспринимает Врага по большей части как когнитивно и ценностно чуждого им субъекта. 69,2 \% респондентов данной группы обладают средним уровнем самоэффективности, 23,1 \% респондентов низким уровнем самоэффективности, 7,7 \% респондентов - высоким уровнем самоэффективности. У 61,5 \% респондентов данной группы ярко выражено самоуважение, у 38,5 \% участников исследования выражено самоуважение.

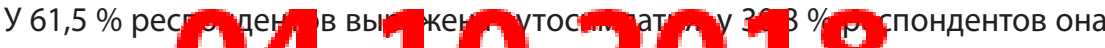
ярко выраж на 76,9 \% респондентов-06наруживанот выратенние ожиданиеположительного отношения других к себе, 15,4% респондентов - ярко выраженное ожидание положительного отношения других к себе. У 7,7 \% участников исследования ожидание положительного отношения других к себе не выражено. 53,8 \% респондентов имеют выраженный самоинтерес, у 38,5 \% респондентов он ярко выражен, у 7,7 \% участников исследования самоинтерес не выражен.

У $18 \%$ респондентов наиболее насыщенной является группа элементов «Взаимная неприязнь, недоброжелательность» (38-54 \% ответов каждого респондента), которой соответствует категория «Субъект враждебных отношений». Эта группа респондентов воспринимает Врага главным образом как человека, недоброжелательно относящегося к ним, к которому они так 


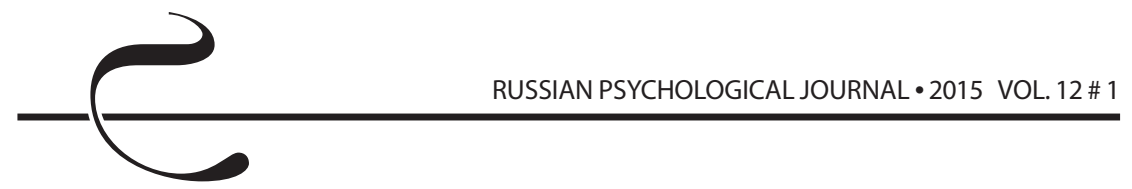

же относятся. 77,8 \% респондентов данной группы обнаруживают средний уровень самоэффективности, 22,2 \% участников исследования обладают низким уровнем самоэффективности. У 44,4 \% респондентов выражено самоуважение, у 33,3 \% участников исследования оно ярко выражено, у $22,2 \%$ респондентов не выражено самоуважение. У $44,4 \%$ респондентов ярко выражена аутосимпатия, у 33,3 \% респондентов она не выражена, у $22,2 \%$ респондентов вь:р - эна аутосимпатия. У $88,9 \%$ респондентов выражено ожидание положительного отношения других к себе, у 11,1 \% респондентов ожидание положительного отношения других к себе выражено ярко. У 44,4 \% участников исследования выявлен ярко выраженный самоинтерес, у 33,3 \% респондентов он выражен, у 22,2 \% респондентов не

«Предательство» (36-44 \% ответов каждого респондента), которой соответствует категория «Субъект манипуляций». Эта группа респондентов воспринимает Врага главным образом как манипулятора, обманщика. 83,3 \% респондентов данной группы обладают низким уровнем выраженности самоэффективности, 16,7 \% респондентов - средним уровнем выраженности самоэффективности. У 83,3 \% респондентов не выражено самоуважение,

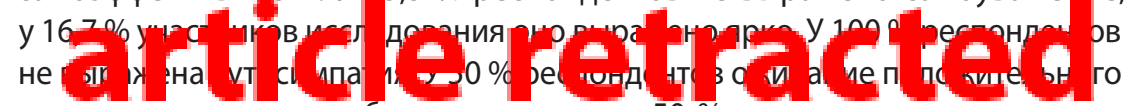
отношения других к себе не выражено, у 50 \% участников исследования выражено ожидание положительного отношения других к себе. у 50 \% респондентов самоинтерес не выражен, 50 \% участников исследования имеют ярко выраженный самоинтерес.

У 8 \% респондентов наиболее насыщенной является группа элементов «Социально неодобряемые качества Врага» (45-52 \% ответов каждого ре-

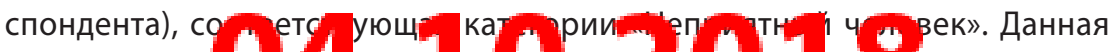

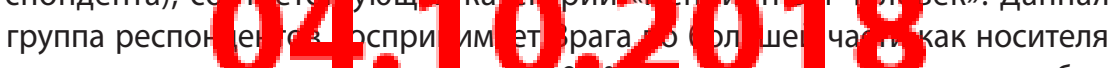
отрицательныхличностных качесть. $100 \%$ респондентов эгии группы обладают низким уровнем самоэффективности, у них не выражено самоуважение. У $100 \%$ респондентов не выражена аутосимпатия. У 75 \% респондентов не выражено ожидание положительного отношения других к себе. 25 \% участников исследования обнаруживают выраженное ожидание положительного отношения других к себе. У 75 \% респондентов не выражен самоинтерес, у 25 \% участников исследования самоинтерес ярко выражен.

Результаты кластерного анализа респондентов, различающихся преобладающими группами элементов представлений о Враге, выраженностью самоуважения, ожидания положительного отношения других к себе, аутосимпатии и самоинтереса, самоэффективности, говорят о возможности 
разделения участников исследования на подгруппы, различающиеся совокупностями особенностей представлений о Враге, самоотношения и самоэффективности.

Полученные результаты позволяют сделать следующие выводы. В рамках данной выборки обнаружены взаимосвязи между особенностями самоотношения личности и уровнем выраженности ее самоэффективности. Субъекты, демонстрирующие высок ‘ ‘ ровни выраженности самоуважения, ожидания положительного отношения других к себе, аутосимпатии и самоинтереса, обладают в основном высоким уровнем выраженности самоэффективности. Субъекты, демонстрирующие низкие уровни выраженности самоуважения, ожидания положительного отношения других к себе, аутосимпатии и само-

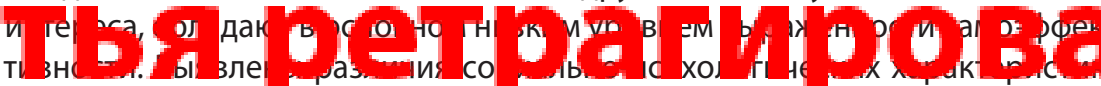
представлений личности о Врагев связи с особенностями ее самоотношения и выраженностью ее самоэффективности. Субъекты, воспринимающие Врага в качестве агрессора, манипулятора, носителя отрицательных качеств, обнаруживают низкие уровни выраженности самоуважения, ожидания отношения других к себе, аутосимпатии и самоинтереса и демонстрируют в основном низкий уровень выраженности самоэффективности. Субъекты,

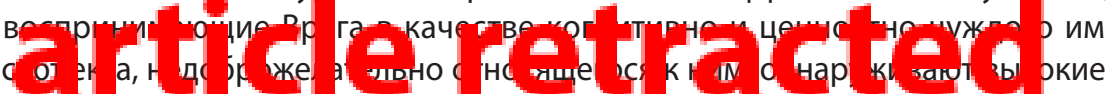
уровни выраженности самоуважения, ожидания отношения других к себе, аутосимпатии и самоинтереса и демонстрируют в основном высокий уровень выраженности самоэффективности.

Результаты проведенного исследования говорят о том, что содержание представлений личности о Враге взаимосвязано с особенностями ее самоотношения и уровнем выраженности ее самоэффективности. Полученные

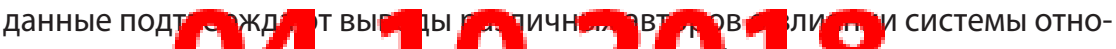

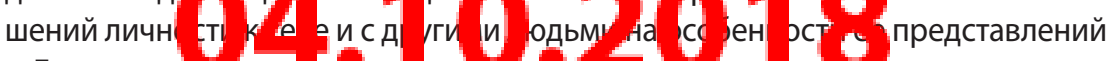
о Другом чельвеке ь разных категория игвидетельствую в пользу выдвинутой гипотезы о том, что социально-психологические характеристики представлений личности о Враге могут различаться в зависимости от особенностей ее самоотношения и уровня выраженности ее самоэффективности. Тем не менее, для проверки общей и частной гипотез необходимо лонгитюдное исследование представлений о Враге, проведенное на большей выборке респондентов. Выводы по результатам исследования, основанные на полученных данных, могут быть использованы в социально-психологическом консультировании с целью коррекции отношений субъекта с окружающими людьми, при разработке программ тренингов толерантности, решения конфликтов в разных сферах взаимодействия. 


\section{Литература}

1. Бреус Е.Д. Особенности представлений об экстремисте-террористе как трудном партнере общения у студенческой молодежи // Российский психологический журнал. - 2010. - Т. 7. - № 5. - С. 31-35.

2. Гайдар М. И. Личностная самоэффективность студентов-психологов // Российский психологический журнал. - 2008. - Т. 5. - № 1. - С. 75-77.

3. Гордеева T. О., Шепелесл ${ }^{\circ}$ А. Тендерные различия в академической и социальной самоэффективности и копинг-стратегиях у современных российскихподростков //Вестник Московского государственногоуниверситета им. М. В. Ломоносова. Сер. 14. Психология. - 2006. - № 3. - С. 78-85.

4. Гудков Л. Идеологема врага. «Враги» как массовый синдром и механизм

5. Емельянова Т.П. Конструированиесоциальных представлений в условиях трансформации российского общества. - М.: Изд-во ИП РАН, 2006. $400 \mathrm{c}$.

6. Знаков В. В. Образ врага как психологическое основание понимания мусульманских террористов россиянами // Вопросы психологии. 2012. - № 2. - С. 23-35.

7.

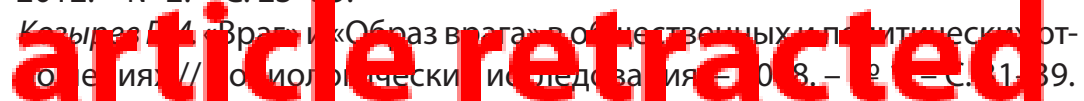

8. Колышко А. М. Психология самоотношения. - Гродно: Изд-во ГрГУ, 2004. - 102 c.

9. Кричевский Р. Л. Самоэффективность и акмеологический подход к исследованию личности // Акмеология. - 2001. - № 1. - С. 47-52.

10. Лабунская В. А. Образ врага в межличностном общении // Социальная психология и общество. - 2013. - № 3. - С. 52-64.

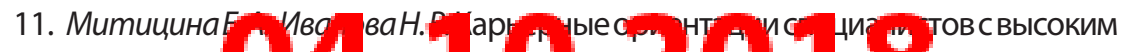
уровнемса о Псковского гсударетвенного универеитста.Сер.Социально-гуманитарные и психолого-педагогические науки. - 2008. - № 5. - С. 121-125.

12. Пантилеев С. Р. Самоотношение как эмоционально-оценочная система. - М.: Изд-во МГУ, 1991. - 108 с.

13. Погорелов А. А. Самоэффективность как предиктор эффективного и безопасного поведения личности // Известия Южного федерального университета. - 2012. - Т. 129. - № 4. - С. 140-145.

14. Столин В. В. Самосознание личности. - М.: Изд-во МГУ, 1983. - 286 с.

15. Тулинова Д. Н. Представления о Враге и Друге в связи с отношением к жизни на различных этапах: дисс. ... канд. психол. наук. - Ростов н/Д, 2005. - 288 c. 
16. Чудова Н. В. Влияние личностных характеристик субъекта на его представления об идеальном партнере по общению // Психологический журнал. - 1993. - Т. 14. - № 3. - С. 28-37.

17. Ширков Ю. Э. Стратегии самокатегоризации в системе представлений о «своих» и «чужих»: автореф. дисс. ... канд. психол. наук. - М., 2009. 29 C.

18. Шкурко Т. А. Отношен:и « "своим/чужим», «близким/далеким» жителей городов разного типа // Социальная психология и общество. - 2013. № 4. - C. 81-94.

19. Doise W. Représentations sociales dans l'identité personnelle / La construction sociale de la personne. - Grenoble: Presses Universitaires de Grenoble,

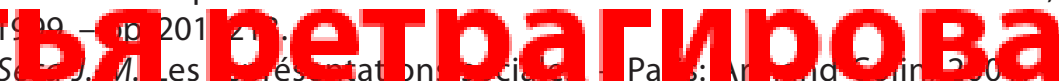
$192 \mathrm{p}$.

\section{article retracted}

\subsection{0 .2018}

